\title{
Prevalence and factors associated with use of herbal medicine among women attending an infertility clinic in Uganda
}

Henry Francisco Kaadaaga ${ }^{1 \dagger}$, Judith Ajeani ${ }^{2+}$, Sam Ononge ${ }^{2}$, Paul E Alele ${ }^{3}$, Noeline Nakasujja ${ }^{4}$, Yukari C Manabe ${ }^{5}$ and Othman Kakaire ${ }^{2^{*}+}$

\begin{abstract}
Background: Infertility is a public health problem associated with devastating psychosocial consequences. In countries where infertility care is difficult to access, women turn to herbal medicines to achieve parenthood. The aim of this study was to determine the prevalence and factors associated with herbal medicine use by women attending the infertility clinic.

Methods: This was a cross-sectional study of 260 women attending the infertility clinic at Mulago hospital. The interviewer administered questionnaire comprised socio-demographic characteristics, infertility-related aspects and information on herbal medicine use. The main outcome measure was herbal medicines use for infertility treatment. Determinants of herbal medicine use were assessed using multivariable logistic regression.

Results: The majority (76.2\%) of respondents had used herbal medicines for infertility treatment. The mean age of the participants was 28.3 years \pm 5.5 . Over $80 \%$ were married, $59.6 \%$ had secondary infertility and $2 / 3$ of the married participants were in monogamous unions. In a multivariable model, the variables that were independently associated with increased use of herbal medicine among infertile patients were being married (OR 2.55, Cl 1.24-5.24), never conceived (OR $4.08 \mathrm{Cl}$ 1.86-8.96) and infertility for less than 3 years (OR $3.52 \mathrm{Cl} 1.51-8.821)$. Factors that were associated with less use of herbal medicine among infertile women were being aged 30 years or less (OR $0.18 \mathrm{Cl} 0.07-0.46)$, primary and no education ( $\mathrm{OR} 0.12 \mathrm{Cl} 0.05-0.46)$ and living with partner for less than three years (OR $0.39 \mathrm{Cl} 0.16-0.93)$.

Conclusions: The prevalence of herbal medicine use among women attending the infertility clinic was $76.2 \%$. Herbal medicine use was associated with the participants' age, level of education, marital status, infertility duration, nulliparity, and duration of marriage. Medical care was often delayed and the majority of the participants did not disclose use of herbal medicines to the attending physician. Health professionals should enquire about use of herbal medicines. This may help in educating the patients about the health risks of using herbal medicine and may reduce delays in seeking appropriate care. Collaboration of health professionals with herbal medicine practitioners would help identify the common herbal medicines used for infertility treatment, their potential benefits and harm.
\end{abstract}

Keywords: Herbal medicine, Infertility, Uganda Sub-Saharan Africa, Traditional medicine

\section{Background}

Infertility is a public health problem in middle and lowresource countries but continues to receive little attention [1]. In many cultures, having children is an essential part of life while infertility is seen in much of Sub-Saharan Africa (SSA) as a personal tragedy, with the potential to impact

\footnotetext{
* Correspondence: kakaireothman@gmail.com

${ }^{\dagger}$ Equal contributors

${ }^{2}$ Department of Obstetrics and Gynecology, Makerere University College of Health Sciences, Kampala, Uganda

Full list of author information is available at the end of the article
}

the entire family or community [1]. It is a dreaded condition that is associated with devastating psychosocial consequences [2-5]. In developing countries, where child-bearing is greatly valued, infertile couples are faced with problems ranging from overt ostracism or divorce to more subtle forms of social stigma leading to isolation and mental distress $[4,6-8]$.

Child bearing is not only a continuation of one's lineage but also economic security. In resource limited settings (RLS) where social security systems are non-existent,

\section{Biomed Central}


parents completely rely on their children for support as they age [9]. Thus married couples are under enormous pressure to procreate [4]. There are many barriers to effective and affordable biomedical infertility care in RLS like Uganda that have poor reproductive health indicators. Infertility treatment and resources are lacking in the formal health sector due more urgent, life-threatening public health issues like maternal mortality [10] and the unmet need for infertility treatment remains large [6]. As a result, biomedical practitioners are often consulted later when religious and traditional methods have failed to provide a solution to the infertility problem $[2,11]$.

Herbal medicine is widely used and a rapidly growing health system of economic importance. In Africa up to $80 \%$ of the population uses traditional medicine to help meet their health care needs [12]. In Asian countries such as China, traditional medicine accounts for around $40 \%$ of all health care delivered [12]. The prevalence of the use and utilization of traditional medicine in Uganda is similar to other parts of Sub-Saharan Africa due to its accessibility and affordability [13]. Traditional Herbal medicines, plants and shrubs extracts, are used to treat various ailments in Uganda. These medicinal plant concoctions are a key component of the primary health care system in Uganda especially in the rural areas [14]. Traditional herbal medicine use has been associated with severe and sometimes fatal complications $[15,16]$. However, many infertile women will take on considerable risk to conceive in order to avoid the social and psychological problems associated with childlessness [9].

The aim of this study was to determine the prevalence and factors associated with the use of traditional herbal medicines among patients presenting to the infertility clinic at Mulago Hospital. Due to the accessibility of traditional medicine, we hypothesized that patients may try herbal medicine first and delay accessing medical clinics.

\section{Methods \\ Design and setting}

This was a descriptive cross-sectional study performed at the infertility clinic of Mulago a national referral and university teaching hospital in Kampala, Uganda, between December 2011 and April 2012. On average, 50 patients attend the weekly infertility clinic. Forty percent of them attending for the first time. The majority (over 95\%) of the patients attending the infertility clinic are females. All newly enrolled clinic patients were consecutively enrolled into the study until the sample size was achieved. According to a study in United Kingdom (UK) by Coulson and Jenkins [17] $40 \%$ of the infertile women had ever used complementary and alternative medicine for treatment of infertility. Using a 5\% significance level and power of 90\%, 260 women attending infertility clinic were enrolled into the study for us to establish the prevalence of Herbal medicine use.

\section{Data collection}

The instrument for data collection (Additional file 1) was pretested among 15 patients attending the infertility clinic one month prior to the commencement of the study. An interviewer-administered structured questionnaire was used to collect the data. The purpose of the study was explained to the patients, and those who consented were interviewed by HFK, JA, OK and trained research assistants. Data was collected in a face-to-face interview. The questionnaire consisted of a demographic and fertility history and a history of use of herbal medicines for the treatment of infertility in the last 12 months prior to attending the infertility clinic. The participant was considered to have used herbs for treatment of infertility if she had swallowed or applied herbal medicines to part of her body. The data was double entered in Epidata version 3.1, cleaned and checked for completeness and exported to Stata 12 (Texas 77845, USA) [18] for analysis.

\section{Statistical analysis}

Descriptive statistics (minimum, maximum, mean, and standard deviation) were applied for continuous variables and simple percentages for categorical variables univariable, bivariable (Table 1) and multivariable logistic regression analysis (Table 2) were used to identify factors which were independently associated with use of herbal medicines. Variables at univariate analysis that had $\mathrm{p}$-value $\leq 0.2$ were entered into a multivariable logistic regression model to determine factors that were independently associated with herbal medicine use. Variables that had P value $\leq 0.05$ were considered statistically significant ( $95 \%$ confidence level).

\section{Ethical consideration}

The study was approved by the department of Obstetrics and Gynecology Mulago hospital, School of Medicine Research and Ethics Committee and Uganda National Council for Science and Technology. The participants gave written informed consent before enrollment into the study. The names and addresses of participants were not included to maintain confidentiality and to elicit an honest response.

\section{Results}

Out of the 280 patients approached, 260 agreed to participate in the study (response rate: 92.9\%). The main reason for refusal to participate in the study was lack of time for the interview. Among the 260 participants attending the infertility clinic, $76.2 \%$ had used herbal medicines for treatment of infertility. The mean age of the participants was 28.3 years \pm 5.5 , $80 \%$ were married, $66 \%$ had secondary infertility and $58 \%$ of the married participants were in monogamous unions. The majority (73.2\%) had used herbal medicines in the last 12 months prior to seeking biomedical care and $63.8 \%$ did not disclose the use of herbal medicines 
Table 1 Demographic and reproductive health characteristics of patients attending the infertility clinic at Mulago hospital

\begin{tabular}{|c|c|c|c|c|c|}
\hline Characteristics & $\begin{array}{l}\text { Ever used herbs } \\
n=198(\%)\end{array}$ & $\begin{array}{l}\text { Never used herbs } \\
n=62(\%)\end{array}$ & $\begin{array}{l}\text { Totals } \\
n=260(\%)\end{array}$ & $\begin{array}{l}\text { Crude } \\
\text { OR/95\% Cl }\end{array}$ & P-value \\
\hline \multicolumn{6}{|l|}{ Age (years) } \\
\hline$\leq 30$ years & 158 (78.8\%) & $34(54.8)$ & $192(73.8)$ & 1 & $<0.01$ \\
\hline$>30$ years & 40 (20.2\%) & $28(45.2)$ & $68(26.2)$ & $0.31(0.17-0.57)$ & \\
\hline \multicolumn{6}{|l|}{ Education level } \\
\hline$\leq$ primary & $93(47.0)$ & $12(19.4)$ & $105(40.4)$ & 1 & $<0.01$ \\
\hline$\geq$ secondary & 105 (53.0) & $50(80.6)$ & 155 (59.6) & $0.27(0.14-0.54)$ & \\
\hline \multicolumn{6}{|l|}{ Religion } \\
\hline Protestant & 78 (39.4) & $18(29.0)$ & $96(36.9)$ & 1 & \\
\hline Catholic & $46(23.2)$ & $30(48.4)$ & $76(29.2)$ & $0.35(0.18-0.71)$ & 0.003 \\
\hline Moslem & $53(26.8)$ & $11(17.7)$ & $64(24.6)$ & $1.11(0.47-2.54)$ & 0.802 \\
\hline Born again & $21(10.6)$ & $3(4.9)$ & $24(9.3)$ & $1.625(0.43-6.01)$ & 0.474 \\
\hline \multicolumn{6}{|l|}{ Marital status } \\
\hline Not married & $30(15.2)$ & $23(37.1)$ & $53(20.4)$ & 1 & $<0.01$ \\
\hline Single & $168(88.8)$ & $39(62.9)$ & 207 (79.6) & $3.30(1.73-6.30)$ & \\
\hline \multicolumn{6}{|l|}{ Type of marriage* } \\
\hline Monogamous & $95(56.6)$ & $27(69.2)$ & $122(58.9)$ & 1 & 0.15 \\
\hline Polygamous & $73(43.4)$ & $12(30.8)$ & $85(41.1)$ & $1.73(.82-3.64)$ & \\
\hline \multicolumn{6}{|l|}{ Ever conceived } \\
\hline No (10 infertility) & $53(26.8)$ & $35(56.5)$ & 88 (33.8) & 1 & $<0.01$ \\
\hline Yes ( $2^{\circ}$ infertility & $145(73.2)$ & $27(43.5)$ & $172(72.2)$ & $3.55(1.96-6.41)$ & \\
\hline \multicolumn{6}{|c|}{ Infertility duration (in Years) } \\
\hline $1-3$ years & $72(36.4)$ & $30(48.4)$ & $102(39.2)$ & 1 & 0.09 \\
\hline$>3$ years & $126(63.6)$ & $32(51.6)$ & $158(60.8)$ & $1.64(.92-2.92)$ & \\
\hline \multicolumn{6}{|c|}{ Duration with partner (in years) ${ }^{* *}$} \\
\hline $1-3$ years & $91(46.9)$ & $20(37.0)$ & $111(42.7)$ & 1 & 0.20 \\
\hline$>3$ years & $103(53.1)$ & $30(63.0)$ & $133(57.3)$ & $1.64(.92-2.92)$ & \\
\hline \multicolumn{6}{|c|}{ Distance from hospital (in KM) } \\
\hline$\leq 5 \mathrm{~km}$ & $81(40.9)$ & $18(29.0)$ & $99(38.1)$ & 1 & \\
\hline $6-10 \mathrm{~km}$ & $72(36.4)$ & $28(45.2)$ & $100(38.5)$ & $0.57(0.29-1.12)$ & 0.103 \\
\hline$>11 \mathrm{~km}$ & $45(22.7)$ & $16(25.8)$ & $61(23.4)$ & $0.63(0.29-1.34)$ & 0.229 \\
\hline \multicolumn{6}{|c|}{ Ever used herbs for other health problem } \\
\hline Yes & $143(72.2)$ & $40(64.5)$ & $183(70.4)$ & 1 & 0.25 \\
\hline No & $55(27.8)$ & $22(35.5)$ & $77(29.6)$ & $0.70(0.38-1.28)$ & \\
\hline \multicolumn{6}{|l|}{ Changed partner } \\
\hline Yes & $134(67.7)$ & $38(61.3)$ & $172(66.2)$ & 1 & 0.35 \\
\hline No & $64(32.3)$ & $24(38.7)$ & $88(33.8)$ & $0.76(0.42-1.37)$ & \\
\hline \multicolumn{6}{|c|}{ Herbal use disclosure } \\
\hline Yes & $68(34.3)$ & 26(41.9) & $94(36.2)$ & 1 & 0.28 \\
\hline No & $130(65.7)$ & $36(58,1)$ & $166(63.8)$ & $0.72(0.40-1.23)$ & \\
\hline
\end{tabular}

*Only married women answered this question.

**16 women were divorced were not currently in any form of relationship. $\mathrm{Km}$ means Kilometers.

OR means Odds ratios.

$\mathrm{Cl}$ Means Confidence intervals. 


\begin{tabular}{|c|c|c|}
\hline Variable & Adjusted OR $(95 \% \mathrm{Cl})$ & P-value \\
\hline Age ( $\leq 30$ versus $>30$ years) & $0.18(0.07-0.46)$ & $<0.001$ \\
\hline \multicolumn{3}{|l|}{ Education level } \\
\hline$(\leq$ primary versus $\geq$ secondary) & $0.12(0.05-0.32)$ & $<0.001$ \\
\hline \multicolumn{3}{|l|}{ Marital status } \\
\hline Married versus Single & $2.55(1.245 .24)$ & 0.011 \\
\hline \multicolumn{3}{|l|}{ Ever conceived } \\
\hline No versus Yes & $4.08(1.86-8.96)$ & $<0.001$ \\
\hline \multicolumn{3}{|l|}{ Duration of stay with partner } \\
\hline ( $1-3$ years versus $>3$ years) & $0.39(0.16-0.93)$ & 0.03 \\
\hline \multicolumn{3}{|l|}{ Duration of infertility } \\
\hline ( $1-3$ years versus $>3$ years) & $3.52(1.51-8.21)$ & 0.004 \\
\hline
\end{tabular}

to the attending physician. Adjusted multivariable analyses are shown in Table 2. The variables that were independently associated with increased use of herbal medicine among infertile patients included being married (OR 2.55, CI 1.24-5.24), nullparity (OR 4.08 CI 1.868.96) and those with infertility for less 3 years (OR 3.52 CI 1.51-8.821). However, factors that were associated with less use of herbal medicine among infertile couples were being 30 year or less (OR $0.18 \mathrm{CI} 0.07-0.46$ ), primary and no education (OR $0.12 \mathrm{CI} 0.05-0.46)$ and living with partner for less than three years (OR 0.39 CI 0.16-0.93).

\section{Discussion}

This study found that $76.2 \%$ of the participants had used herbal medicines to treat their infertility prior to seeking care at a medical clinic. These findings are lower than the estimates in a Turkish study where complementary and alternative medicines (CAM) were utilized by $82 \%$ of the infertile women [19]. However, it is higher than the $66 \%$ reported by Stankiewicz et.al among patients attending a reproductive health unit in Australia [20]. In Africa, traditional medical practice is a key resource for information, coping and herbal medication for health problems. The World Health Organization (WHO) estimates that use of herbal medicines on the African continent is widespread and prevalent [12]. The use of CAM by infertile patients is high worldwide $[20,21]$. There is a growing body of evidence that shows that a significant number of women or couples rely on CAM to enhance fertility or treat infertility $[11,17,20-28]$. Globally, the use of CAM by infertile couples or women varies considerably from $12 \%$ [26] to $91 \%$ [24]. A study among Lebanese women seeking infertility treatment showed that $41 \%$ of the women used CAM [23]. Similarly a study in the UK found out that $40 \%$ of 400 infertile women had used CAM as a therapy for infertility treatment [17].
However, in the United States (US) only 17\% of infertile couples use herbal medicines [22].

We found a higher prevalence of herbal medicine use by women who were married and those who had never conceived. However, women who were less than 30 years of age and those who were less educated were less likely to use herbal medicines. Women who are educated are more likely to have some income that they use to pay for herbal medical treatment. Several studies have showed that older women, who are better-educated and employed with high incomes, are more likely to use CAM [20,22,24,29,30]. Addo and colleagues in Ghana, however, found that under privileged women attending the gynecological clinic were more likely to utilize herbal medications in the management of their infertility [27].

Our study shows that patients with infertility presented late to medical doctors for care. The majority of the participants presented after more than three years of infertility and did not disclose the use of herbs to the attending physician. This finding was similar to a study in Lebanon that showed that disclosure of CAM use to the attending physicians was low [23].

The participants who had been staying with a partner for more than three years were four times more likely to use herbal medications. The purpose of marriage in the African setting is procreation [2] and if a woman fails to conceive soon after marriage, couples seek for help and some opt for traditional herbal medicines as a solution [31]. The majority of the participants sought biomedical care for infertility after three years of failing to achieve a pregnancy. This could have been due to the lack of comprehensive infertility treatment in the mainstream public health care system in Uganda. Thus, women tried traditional medical practitioners first and it is only when they failed to conceive that they searched for the appropriate medical clinics. However, it is also known that the success of biomedical infertility treatment decreases with longer duration of infertility [32,33] and use of herbal medicines may reduce chances of conception [34]. Herbal medicines should be used with caution since they may worsen the infertility problem $[35,36]$. Evidence shows that phytoestrogens present in herbal medications exert negative estrogenic effects on implantation [35,36], adversely affecting pregnancy outcomes of biomedical treatment. Concurrent use of CAM and modern medical treatment for infertility has been shown to decrease pregnancy and live birth rates [37].

Our study acknowledges the following limitations. First, recruitment of participants took place in an infertility clinic at a national referral hospital which might have led to an underestimation of the prevalence of herbal medicine use since surveyed subjects have a potential bias toward conventional treatment. Second, given that participants were recruited from only one clinical setting, the results 
of the study may not be generalizable to the general population. However, the infertility clinic at Mulago national referral is the largest unit for infertility treatment in Uganda and is a major referral center for the treatment of infertility. The patients who are seen in this clinic are from different social and cultural background and were at different levels of infertility care. The results could be representative of the whole spectrum of the infertility problem in Uganda. Thirdly, this was a cross sectional study which does not allow us to establish causality between the various correlates and herbal medical use. Finally, the possibility of a recall bias cannot be ruled out in self-reports concerning herbal medical use.

\section{Conclusion}

This study shows that $76.2 \%$ of the women attending the infertility clinic had used herbal medicines prior to seeking bio-medical care. Herbal medicine use was associated with the women's age, level of education, marital status, duration of infertility, prior history of conception, and duration of stay with the spouse. At present, health care professionals do not routinely enquire about the use of herbal medicines. It is important that health professionals enquire from the patients about past or current use of herbal medicines. This may help in educating the patients about the health risks of using herbal medicine and may reduce delays in seeking appropriate care. Collaboration of health professionals with herbal medicine practitioners would help identify the common herbal medicines used for infertility treatment, their potential benefits and harm.

\section{Additional file}

Additional file 1: Study instrument.

\section{Competing interests}

The authors declare that they have no competing interests.

\section{Authors' contributions}

HFK, OK, JA conceived the study; HFK,JA, OK carried out the data collection; SO and OK analyzed the data; OK wrote the first draft; All authors contributed to the manuscript, read and approved the final version.

\section{Acknowledgements}

"The work was supported by Grant Number 5R24TW008886 supported by OGAC, NIH and HRSA. Its contents are solely the responsibility of the authors and do not necessarily represent the official views of the supporting offices." The authors would like to thank the participants for taking off time to participate in this study.

\section{Author details}

'Department of Obstetrics and Gynecology, Hoima regional Referral Hospital, Hoima, Uganda. ${ }^{2}$ Department of Obstetrics and Gynecology, Makerere University College of Health Sciences, Kampala, Uganda. ${ }^{3}$ Department of Pharmacology, Mbarara University of Science \& Technology, Mbarara, Uganda. ${ }^{4}$ Department of Psychiatry, School of Medicine Makerere University College of Health Sciences, Kampala, Uganda. ${ }^{5}$ Division of Infectious Diseases, Department of Medicine, Johns Hopkins University, Baltimore, MD, USA.
Received: 5 June 2013 Accepted: 10 January 2014

Published: 16 January 2014

\section{References}

1. Ombelet W, Cooke I, Dyer S, Serour G, Devroey P: Infertility and the provision of infertility medical services in developing countries. Hum Reprod Update 2008, 14(6):605-621.

2. Okonofua FE, Harris D, Odebiyic A, Kane T, Rachel C, Snow CR: The social meaning of infertility in Southwest Nigeria. Health Trans Rev 1997, 7:205-220.

3. Gerrits T, Shaw M: Biomedical infertility care in sub-Saharan Africa: a social science review of current practices, experiences and viewpoints. F, V \& V In ObGYn 2010, 2(3):194-207.

4. Tabong PTN, Adongo PB: Infertility and childlessness: a qualitative study of the experiences of infertile couples in Northern Ghana. BMC Pregnancy Childbirth 2013, 13:72. 2013, 13(72).

5. Mumtaz Z, Shahid U, Levay A: Understanding the impact of gendered roles on the experiences of infertility amongst men and women in Punjab. Reprod Health 2013, 10:3.

6. Dyer SJ: Infertility-related reproductive health knowledge and help-seeking behaviour in African countries. Hum Reprod 2008, 1:29-33.

7. Tabong PTN, Adongo PB: Understanding the social meaning of infertility and childbearing: a qualitative study of the perception of childbearing and childlessness in Northern Ghana. PLoS One 2013, 8(1):e54429.

8. Wischmann T, Stammer H, Scherg H, Gerhard I, Verres R: Psychosocial characteristics of infertile couples: a study by the Heidelberg fertility consultation service. Hum Reprod 2001, 16:1753-1761.

9. Adewunmi AA, Etti EA, Tayo AO, Rabiu KA, Akindele RA, Ottun TA, Akinlusi FM: Factors associated with acceptability of child adoption as a management option for infertility among women in a developing country. Int J Womens Health 2012, 4:365-372.

10. UDHS: Uganda Demographic and Health. UBOS Calverton, Maryland, USA Uganda Bureau of Statistics (UBOS) and Macro International Inc 2012; 2011.

11. Rayner JA, McLachlan HL, Forster DA, Cramer R: Australian women's use of complementary and alternative medicines to enhance fertility: exploring the experiences of women and practitioners. BMC Complement Altern Med 2009, 9:52.

12. WHO: Traditional Medicine Strategy 2002-2005. Geneva, Switzerland; 2002 whalibdoc.who.int/hq/2002/who_edm_trm_2002.1.pdf.

13. Kamatenesi-Mugisha $\mathrm{M}$, Oryem-Origa $\mathrm{H}$ : Traditional herbal remedies used in the management of sexual impotence and erectile dysfunction in western Uganda. Afr Health sci 2005, 5(1):40-49.

14. Kamatenesi-Mugisha M, Hoft R, Bukenya Ziraba R: Ethnomedical use of Rytigynia (nyakibasi) in Bwindi Impenetrable National Park, SW Uganda. Nordic J Botany, LIDLA 2000, 5(4):97-108.

15. Geraldine $M$, Venkatesh $T$ : Lead poisoning as a result of infertility treatment using herbal remedies. Arch Gynecol Obstet 2007, 275(4):279-281.

16. Otieno LS, McLigeyo SO, Luta M: Acute renal failure following the use of herbal remedies. East Afr Med J 1991, 68(12):993-998.

17. Coulson C, Jenkins J: Complementary and alternative medicine utilisation in NHS and private clinic settings: a United Kingdom survey of 400 infertility patients. J Exp Cli Assist Reprod 2005, 2(1):5.

18. StataCorp: Stata Statistical Software: Release 12. College Station, TX: StataCorp LP. Texas 77845 USA; 2012

19. Edirne T, Arica SG, Gucuk S, Yildizhan R, Kolusari A, Adali E, Can M: Use of complementary and alternative medicines by a sample of Turkish women for infertility enhancement: a descriptive study. BMC Complement Altern Med 2010, 10:11.

20. Stankiewicz M, Smith C, Alvino H, Norman R: The use of complementary medicine and therapies by patients attending a reproductive medicine unit in South Australia: a prospective survey. Aust N Z J Obstet Gynaecol 2007, 47(2):145-149.

21. Bardaweel SK, Shehadeh M, Suaifan GA, Kilani MV: Complementary and alternative medicine utilization by a sample of infertile couples in Jordan for infertility treatment: clinics-based survey. BMC Complement Altern Med 2013, 13:35.

22. Smith JF, Eisenberg ML, Millstein SG, Nachtigall RD, Shindel AW, Wing $H$, Cedars M, Pasch L, Katz PP: The use of complementary and alternative fertility treatment in couples seeking fertility care: data from a prospective cohort in the United States. Fertil Steril 2010, 93(7):2169-2174. 
23. Ghazeeri GS, Awwad JT, Alameddine M, Younes ZM, Naja F: Prevalence and determinants of complementary and alternative medicine use among infertile patients in Lebanon: a cross sectional study. BMC Complement Altern Med 2012, 12:129.

24. Galst J: Alternative medicine and infertility: What infertility patients are using and why. Fertil Steril 1999, 72:S128.

25. Sundby J, Mboge R, Sonko S: Infertility in the Gambia: frequency and health care seeking. Soc Sci Med 1998, 46(7):891-899.

26. van Balen F, Verdurmen J, Ketting E: Choices and motivations of infertile couples. Patient Educ Couns 1997, 31:19-27.

27. Addo V: Herbal medicines: socio-demographic characteristics and pattern of use by patients in a tertiary obstetrics and gynaecology unit. J Sci Technol (Ghana) 2007, 27(3):149-155.

28. Ayaz S, Efe SY: Traditional practices used by infertile women in Turkey. Int Nurs Rev 2010, 57(3):383-387.

29. Rayner JA, Willis K, Burgess R: Women's use of complementary and alternative medicine for fertility enhancement: a review of the literature. J Altern Complement Med 2011, 17(8):685-690.

30. Schaffir J, McGee A, Kennard E: Use of nonmedical treatments by infertility patients. J Reprod Med 2009, 54(7):415-420.

31. Barden-O'Fallon J: Unmet fertility expectations and the perception of fertility problems in a Malawian village. Afri J Reprod health 2005, 9(2):14-25.

32. Tomlinson MJ, Amissah-Arthur JB, Thompson KA, Kasraie JL, Bentick B Prognostic indicators for intrauterine insemination (IUI): statistical model for IUI success. Hum Reprod 1996, 11(9):1892-1896.

33. Dunphy BC, Neal LM, Cooke ID: The clinical value of conventional semen analysis. Fertil Steril 1989, 51(2):324-329.

34. Kumar D, Kumar A, Prakash O: Potential antifertility agents from plants: a comprehensive review. J Ethnopharmacol 2012, 140(1):1-32.

35. Mukhram MA, Shivakumar H, Viswanatha GL, Rajesh S: Anti-fertility effect of flower extracts of Tabernaemontana divaricata in rats. Chin $J$ Nat Med 2012, 10(1):58-62.

36. Rosselli M, Reinhart K, Imthurn B, Keller PJ, Dubey RK: Cellular and biochemical mechanisms by which environmental oestrogens influence reproductive function. Human Reprod Update 2000, 6(4):332-350.

37. Boivin JSL: Use of complementary and alternative medicines associated with a 30\% lower ongoing pregnancy/live birth rate during 12 months of fertility treatment. Hum Reprod 2009, 24:1626-1631.

doi:10.1186/1472-6882-14-27

Cite this article as: Kaadaaga et al.: Prevalence and factors associated with use of herbal medicine among women attending an infertility clinic in Uganda. BMC Complementary and Alternative Medicine 2014 14:27.

\section{Submit your next manuscript to BioMed Central and take full advantage of:}

- Convenient online submission

- Thorough peer review

- No space constraints or color figure charges

- Immediate publication on acceptance

- Inclusion in PubMed, CAS, Scopus and Google Scholar

- Research which is freely available for redistribution

Submit your manuscript at www.biomedcentral.com/submit
Biomed Central 